\title{
Antibacterial Activity of Honey on Staphylococcus aureus and Streptococcus pyogenes Isolated from Wound Pus ${ }^{\dagger}$
}

\author{
Ivangelin Sneha P. ${ }^{1 *}$ \\ 1 Department of Microbiology, Kamaraj College, Thoothukudi- 628002, Tamil Nadu \\ * Correspondence: ivangelinsneha23@gmail.com; \\ $\dagger$ Presented at International e-Conference on Bioengineering for Health and Environment (ICBHE 2020)
}

Received: 5.07.2020; Revised: 10.07.2020; Accepted: 12.07.2020; Published: 15.07.2020

\begin{abstract}
Antibacterial activity of honey obtained from an apiculture farm was tested on Staphylococcus aureus and Streptococcus pyogens isolated from wound pus was observed. Agar well diffusion method was used to determine the antibacterial activity of honey on the test organisms. Moreover, the result was that the honey sample had heavy antibacterial activities against the test organisms, which was revealed by the zone of inhibition obtained. The antibacterial activity increased with the increase in concentrations of honey and showed a clear zone for both organisms. Therefore honey can be accepted as an antibacterial agent for the treatment of wounds, burns, bedsores, and ulcers.
\end{abstract}

Keywords: Antibacterial activity; Honey; Staphylococcus aureus; Streptococcus pyogens.

(C) 2020 by the authors. This article is an open-access article distributed under the terms and conditions of the Creative Commons Attribution (CC BY) license (https://creativecommons.org/licenses/by/4.0/).

\section{Funding}

This research received no external funding.

\section{Acknowledgments}

This research has no acknowledgment.

\section{Conflicts of Interest}

The authors declare no conflict of interest. 